\title{
Surgical experience in the management of spontaneous pneumothorax, 1972-82
}

\author{
DAVID WEEDEN, GEOFFREY H SMITH
}

From the Department of Cardiothoracic Surgery, Northern General Hospital, Sheffield

ABSTRACT In the past 11 years 233 patients have undergone 241 parietal pleurectomies for either recurrence of their spontaneous pneumothorax or failure to respond adequately to management by tube drainage. Major complications occurred in $3.7 \%$ of cases, with transaxillary apical pleurectomy engendering significantly fewer complications than full pleurectomy through a posterolateral thoracotomy. The significantly larger number of minor complications, however, in patients undergoing full pleurectomy was largely due to the larger number of patients with chronic obstructive lung disease in this group. On the basis of our experience we advocate the use of transaxillary apical pleurectomy for the younger age group with recurrent pneumothoraces and a full pleurectomy in the older age group, who frequently present because of failure to respond satisfactorily to tube drainage during their initial pneumothorax and often have lung disease secondary to chronic obstructive lung disease which is not confined to the apex of the upper lobe.

De Vries and Wolfe ${ }^{1}$ have estimated that about one in 500 young men in the United States will develop a spontaneous pneumothorax. Ferguson et $\mathrm{al}^{2}$ calculated the incidence of new cases of spontaneous pneumothorax in the population in Glasgow and found it to be 78 cases per million. According to Cran and Rumball, ${ }^{3}$ the incidence of spontaneous pneumothorax is increasing.

Once diagnosed $80-90 \%$ of cases will resolve with observation or tube drainage. ${ }^{24}$ There are three major problems in the management of a pneumothorax that may call for surgical intervention. Firstly, a continuing air leak may be present requiring surgery to seal the leak. Secondly, the initial treatment may prove successful but the patient's respiratory reserve may be so diminished that a further episode must be actively prevented. Finally, repeated recurrences, even if not risking the patient's life, are socially and economically undesirable.

\section{Patients and methods}

We reviewed the clinical case notes and chest radiographs of all patients admitted to our unit from 1

Address for reprint requests: Mr David Weeden, Department of Cardiothoracic Surgery, Northern General Hospital, Sheffield.

Accepted 15 June 1983
January 1972 to 31 December 1982 either with a recurrence of spontaneous pneumothorax or after failure of tube drainage. We excluded those patients with traumatic pneumothoraces and those undergoing thoracotomy for a complication of tube drainage other than failure of the pneumothorax to resolve. We identified 233 patients fulfilling these criteria. Follow up data were compiled from information supplied by outpatient review or postal inquiry to the patients and their general practitioners.

Removal of the parietal pleura from the costal surface, the apex, and the mediastinum above the lung hilum was performed through a posterolateral thoracotomy through the bed of the fifth rib without division of the posterior end of the rib. This closely follows the original description of the operation by Gaensler $^{5}$ and is called full pleurectomy in this report. All apical pleurectomies were performed through an axillary incision with division of the intercostal muscles and entry to the chest through the bed of the fourth rib without division of the posterior end; only the pleura at the apex was removed. During both procedures sites of air leak and obvious bullae were oversewn with fine nonabsorbable monofilament sutures. In 12 full pleurectomies a decortication was required to allow full expansion of the lung. One or two intercostal drains were inserted, depending on the degree of air leak and the adequacy of haemostasis. In the past three 
years continuous infusion thoracic epidural analgesia has been used.

We based our diagnosis of chronic obstructive lung disease on the 1965 report of the British Medical Research Council Committee on the Aetiology of Chronic Bronchitis, which defined chronic generalised airways obstruction as "simple chronic bronchitis" (chronic or recurrent increase in the volume of mucoid bronchial secretion sufficient to cause expectoration) with associated irreversible or partially reversible slowing of forced expiration. In clinical terms this was taken to mean a history of cough productive of mucoid or mucopurulent sputum on most days for at least three months of the year for at least three successive years, together with wheezing attacks. The diagnosis of emphysema was by radiology, the criteria being a low flat diaphragm, a long thin heart shadow, diminished lung markings, and an enlarged retrosternal space on the lateral film.

All the statistical comparisons between groups were made by the $\chi^{2}$ test and between means by Student's $t$ test. Means are followed when appropriate by either the standard deviation (in parenthesis) or the range.

\section{Results}

Two hundred and thirty three patients (eight having operations on both sides at different times) underwent 241 thoracotomies with 74 apical pleurectomies, 155 full pleurectomies, and 12 full pleurectomies with an added decortication.

Age the mean age for all patients was 41.4 (SD 21.4 ) years, range 3-87 years. The distribution of age by decades is shown in the top histogram in the figure, the highest incidence being in the third and sixth decades. There was a clear age difference between those having an apical pleurectomy-27.1 (8.6) years, range $12-52$ years-and those having a full pleurectomy-48.8 (21.7) years, range 3-87 years $(t=3.70, \mathrm{p}<0.0005)$. A similar difference in age was seen between those with chronic obstructive lung disease-51.9 (22.4) years, range 22-85 years - and those without chronic obstructive lung disease $-34.0(18.7)$ years, range $3-87$ years $(t=$ $3 \cdot 16, \mathrm{p}<0.0025)$.

Sex distribution The overall male:female ratio was $2 \cdot 5: 1$, with men outnumbering women increasingly with advancing age: the male:female ratio in the 10-39 year group was $2 \cdot 3: 1$ compared with $6 \cdot 1: 1$ in the $60-89$ year group $\left(\chi^{2}=5.47, p<0.025\right)$. The distribution of the sexes by decades is shown in the top histogram.

Side affected Two hundred and five patients $(88 \%)$ had episodes of pneumothorax on one side only,

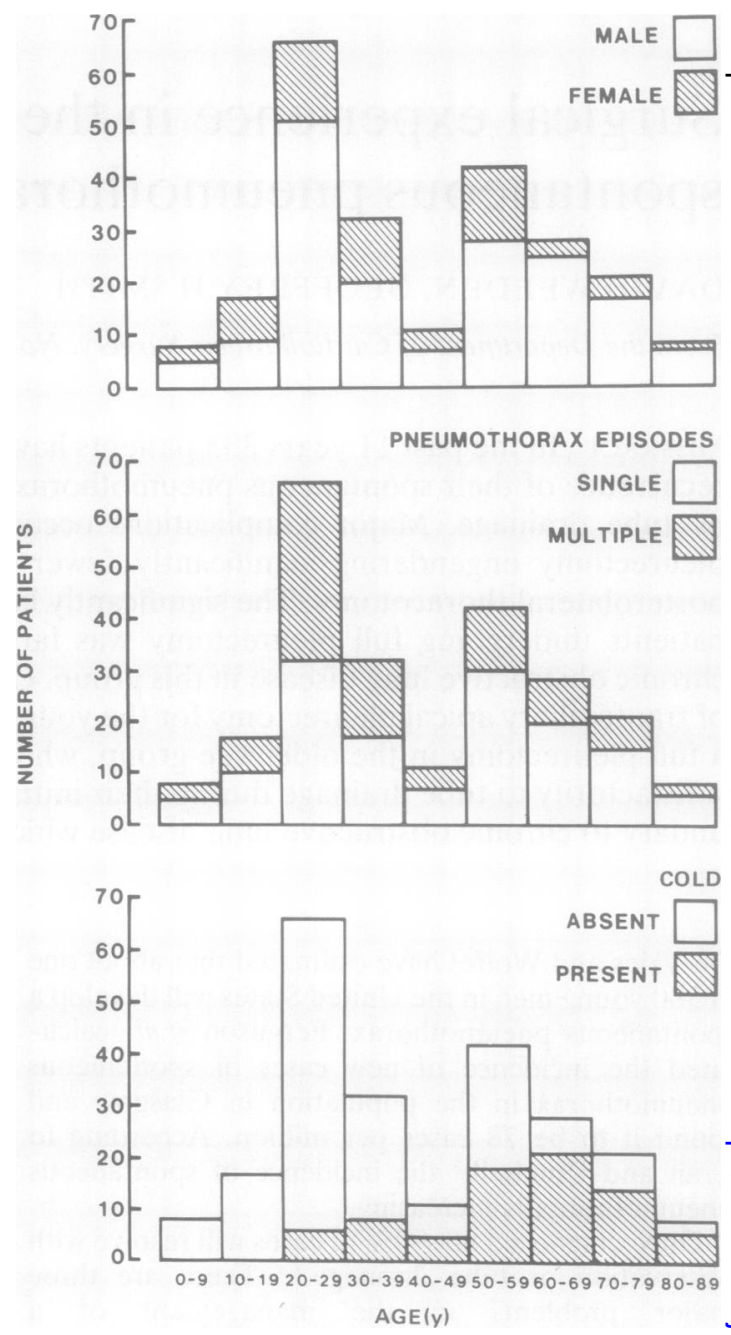

Sex, number of pneumothoraces, and presence or absence of chronic obstructive lung disease (COLD) of the 233 patients studied, subdivided by age.

with a right:left ratio of $3: 2(124: 81)$. Twenty eight patients $(12 \%)$ had documented bilateral episodes with a right:left ratio of $1: 1(65: 60)$. There was no $\sigma$ significant difference between these ratios. Only $N$ three patients $(1.3 \%)$ had bilateral pneumothoraces which occurred simultaneously.

Recurrence before surgery Ninety one patients (39\%) suffered more than one pneumothorax, with a mean of 3.4 episodes per patient (range 2-8). Fifty eight of these ninety one patients $(64 \%)$ had more than two episodes. The age distribution of those failing to resolve during their initial episode (single episode) and of those who suffered more than one pneumothorax (multiple episodes) is shown in the 
Table 1 Associated respiratory disease in the 233 patients studied

\begin{tabular}{ll}
\hline Associated disease & No of patients \\
\hline Chronic obstructive lung disease & 54 \\
alone & 18 \\
with emphysema & 6 \\
with pneumoconiosis & 8 \\
Asthma & 7 \\
Pneumoconiosis & 3 \\
Cystic fibrosis & 1 \\
Fibrosing alveolitis & \\
\hline
\end{tabular}

middle histogram.

Associated respiratory conditions These are shown in table 1. Chronic obstructive lung disease was present alone or in association with other respiratory disorders in 78 patients $(33.5 \%)$, and was more common with increasing age. The age distribution of patients with and without chronic obstructive lung disease is shown in the lower histogram. In the patients with chronic obstructive lung disease, the clinical severity of exertional dyspnoea was recorded, the New York Heart Association (NYHA) classification for dyspnoea being used. Twelve patients were grade I, 42 grade II, 20 grade III, and four grade IV. One hundred and twenty eight patients were tobacco smokers $(55 \%)$.

Indications for operation The indications for the 241 pleurectomies are listed in table 2 . A persistent air leak was defined as one lasting for four days or more. A persistent air leak was more often an indication in those having full pleurectomy and recurrence was more often the indication in those having apical pleurectomy. Decortication was required more often in those who had had a failed chemical pleurodesis or inadequate lung expansion after tube drainage.

Site of air leak This was recorded at thoracotomy and is shown in table 3. Most young patients have disease at the apex of the upper lobe, but significantly more patients with chronic obstructive lung disease have leaks at other sites, with or without a leak at the upper lobe apex.

Blood loss The operative blood loss, estimated by swab weighing, was added to the postoperative blood loss, obtained by drainage. The mean total
Table 3 Site of air leak in 241 pleurectomies (percentages of total in parentheses)

\begin{tabular}{llll}
\hline Site of leak & All cases & With COLD & Without COLD \\
\hline $\begin{array}{l}\text { Apex, } \\
\text { upper lobe }\end{array}$ & $144(59.8)$ & $39^{*}(49 \cdot 4)$ & $105^{*}(64 \cdot 8)$ \\
$\begin{array}{l}\text { Other site with } \\
\text { or without leak } \\
\text { at apex }\end{array}$ & $58(24 \cdot 1)$ & $26 \dagger(32.9)$ & $32 \dagger(19.8)$ \\
$\begin{array}{l}\text { No visible } \\
\text { leak }\end{array}$ & $39(16 \cdot 1)$ & $14(17 \cdot 7)$ & $25(15.4)$ \\
\hline
\end{tabular}

Significant differences: ${ }^{*} \chi^{2}=6.09, \mathrm{p}<0.025 ; \dagger \chi^{2}=6.09, \mathrm{p}<0.025$ COLD-Chronic obstructive lung disease.

loss for full pleurectomy (391 (173) $\mathrm{ml}$, range 150 $910 \mathrm{ml})$ was just significantly more $(t=2 \cdot 04, \mathrm{p}<$ 0.05 ) than that lost by those having an apical pleurectomy (286 (125) $\mathrm{ml}$, range $120-820 \mathrm{ml})$. The blood loss for the two patients who were reexplored, not included in the above figures, was $1370 \mathrm{ml}$ for the apical pleurectomy and $1450 \mathrm{ml}$ for the full pleurectomy.

Postoperative air leak An air leak was present after 53 pleurectomies $(22 \%)$, but ceased within 24 hours in all but 14 cases, the longest persisting for six days. Eight of the prolonged leaks occurred in patients with chronic obstructive lung disease, which was just significantly more $\left(\chi^{2}=3.70, p<0.05\right)$ than the six occurring in those without chronic obstructive lung disease.

Hospital stay The postoperative hospital stay for the different types of procedure for all cases and those with and without complications is shown in table 4 . There are no significant differences between any of the figures.

Complications Tables 5 and 6 show the complications, the major ones being death, respiratory failure requiring postoperative mechanical ventilation, and haemorrhage requiring re-exploration and the minor complications immediate contralateral pneumothorax after surgery requiring drainage, residual apical pneumothorax after removal of drains requiring an apical drain, chest infection productive of purulent sputum, sputum retention requiring bronchoscopy, wound infection, and deep vein thrombosis. Major complications occurred in

Table 2 Indications for operation in 241 pleurectomies (percentages of total in parentheses)

\begin{tabular}{|c|c|c|c|c|}
\hline \multirow[t]{2}{*}{ Indication } & \multicolumn{4}{|c|}{ Type of pleurectomy } \\
\hline & All types & Apical & Full & Full plus decortication \\
\hline $\begin{array}{l}\text { Persistent air leak } \\
\text { Recurrence } \\
\text { Collapse on clamping drain } \\
\text { Inadequate expansion } \\
\text { Failure of chemical pleurodesis }\end{array}$ & 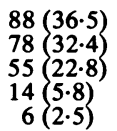 & $\begin{array}{l}21 *(28 \cdot 4) \\
35 \dagger(47 \cdot 3) \\
16(21 \cdot 6) \\
2 \ddagger(2 \cdot 7) \\
-\end{array}$ & $\begin{array}{c}66^{*}(42 \cdot 6) \\
43+(27 \cdot 7) \\
37(23 \cdot 9) \\
58(3 \cdot 2) \\
4^{* *}(2 \cdot 6)\end{array}$ & $\begin{array}{l}1(8 \cdot 3) \\
\overline{2}(16 \cdot 7) \\
7 \neq \$(58 \cdot 3) \\
2 * *(16 \cdot 7)\end{array}$ \\
\hline
\end{tabular}

Significant differences: ${ }^{*} \chi^{2}=4.29, p<0.05 ; \dagger \chi^{2}=8.53, p<0.005 ; \ddagger \chi^{2}=34 \cdot 1, p<0.0005 ; 8 \chi^{2}=50.7, p<0.0005 ;{ }^{* *} \chi^{2}=6.38, p<0.025$. 
Table 4 Mean (SD) number of days in hospital after operation

\begin{tabular}{|c|c|c|c|}
\hline $\begin{array}{l}\text { Type of } \\
\text { pleurectomy }\end{array}$ & All cases & Uncomplicated & Complicated \\
\hline Apical & $8 \cdot 5(3 \cdot 1)$ & \multirow{3}{*}{$\begin{array}{l}8 \cdot 0(1 \cdot 9) \\
(\mathrm{n}=67) \\
9 \cdot 3(2 \cdot 5) \\
(\mathrm{n}=119) \\
10 \cdot 0(2 \cdot 0) \\
(\mathrm{n}=7)\end{array}$} & \multirow{3}{*}{$\begin{array}{l}13 \cdot 5(4 \cdot 3) \\
(n=7) \\
13 \cdot 9(4 \cdot 9) \\
(n=36) \\
23 \cdot 4(18 \cdot 4) \\
(n=5)\end{array}$} \\
\hline Full & $10 \cdot 5(3 \cdot 8)$ & & \\
\hline $\begin{array}{l}\text { Full plus } \\
\text { decortication }\end{array}$ & $16 \cdot 5(14 \cdot 5)$ & & \\
\hline
\end{tabular}

$3.7 \%$ of operations, with no significant difference between the apical and full procedures; whereas minor complications occurred significantly less often after apical pleurectomy $(8 \cdot 1 \%)$ than after full pleurectomy (18.7\%).

Effect of epidural analgesia Only 52 patients had epidural analgesia so there are insufficient numbers to allow analysis of all combinations of procedure and the presence of chronic obstructive lung disease. There was, however, a strong clinical impression of fewer chest related complications in those with epidural pain relief than in the others. Epidural analgesia was used in 42 of the 155 full pleurectomies and in the whole group there were 18 chest related complications (11 with purulent sputum and seven with sputum retention). Three complications $(7.1 \%)$ occurred in the epidural group and 15 $(13.3 \%)$ in the non-epidural group, but the difference did not achieve significance.

Respiratory function Preoperative expiratory forced vital capacity (FVC), FVC/FEV 1 ratio, and peak expiratory flow (measured with a Wright spirometer) were determined in random selected patients-in 30 having apical pleurectomy and 30 having full pleurectomy (15 with and 15 without chronic obstructive lung disease). The NYHA grade for those with chronic obstructive lung disease was I in three patients, II in eight, III in three, and IV in one case, which closely resembles the distribution of the NYHA grades for all the patients with chronic obstructive lung disease. None of those tested had a significant air leak from the chest drain. The patients were tested again six to ten months after operation (table 7). Within the groups there were no

Table 5 Deaths and major complications

\begin{tabular}{llll}
\hline & \multicolumn{3}{l}{ Type of pleurectomy } \\
\cline { 2 - 4 } & Apical & Full & $\begin{array}{l}\text { Full plus } \\
\text { decortication }\end{array}$ \\
\hline Death & - & 3 & - \\
$\begin{array}{l}\text { Respiratory failure } \\
\text { Haemorrhage }\end{array}$ & - & 3 & 1 \\
\hline & 1 & 1 & - \\
\hline
\end{tabular}

${ }^{*}$ Not significantly different.
Table 6 Numbers of minor complications

\begin{tabular}{llll}
\hline & \multicolumn{2}{l}{ Type of pleurectomy } \\
\cline { 2 - 4 } & Apical & Full & $\begin{array}{l}\text { Full plus } \\
\text { decortication }\end{array}$ \\
\hline Contralateral episode & 2 & 5 & - \\
Apical pneumothorax & 1 & 2 & 1 \\
Chest infection & 2 & 11 & 2 \\
Sputum retention & 1 & 7 & 1 \\
Wound infection & - & 3 & - \\
Deep vein thrombosis & - & 1 & - \\
\hline Total & $6^{*}$ & $29^{*}$ & 4 \\
\hline
\end{tabular}

*Significant difference, $\chi^{2}=4 \cdot 35, p<0 \cdot 05$.

significant changes after operation and among the patients who had full pleurectomy the difference in the changes between those with and without chronic obstructive lung disease does not achieve significance. The pattern of results in table 7 is the same when the data are expressed as percentages of the predicted values.

Recurrence after surgery The recurrence rate in this group of patients is $0.43 \%$ (one in 233 patients) with a $97 \%$ follow up over a mean period of 56 months (range 5-137 months). Seven patients (four apical pleurectomies, four full pleurectomies with or without decortication) have been lost to follow up. Twelve patients (one apical pleurectomy, eleven full pleurectomies with or without decortication) have died during the period of follow up without evidence of recurrence. Sixty five patients are alive after 69 apical pleurectomies without any recurrences and 149 patients are alive after 151 full pleurectomies (with or without decortication) with only a single recurrence, which occurred three months after operation (one recurrence after $151+11$ full pleurectomies with or without decortication $=0.62 \%$ ).

Table 7 Mean (SD) results of respiratory function tests

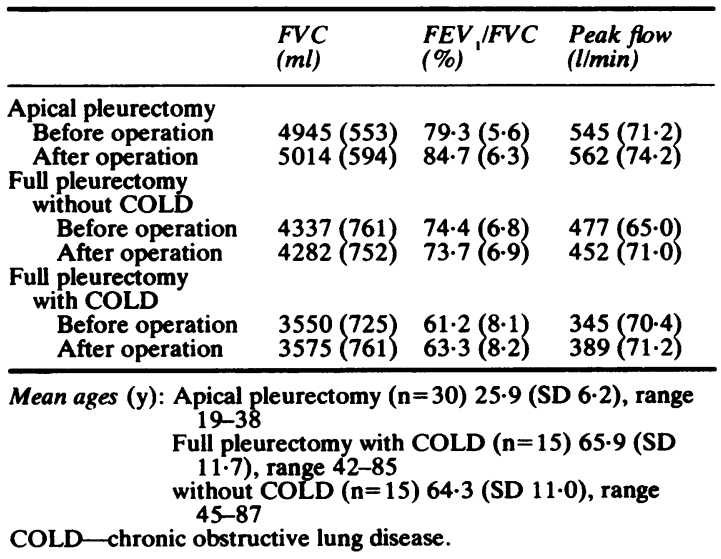

COLD - chronic obstructive lung disease. 


\section{Discussion}

The risk of a further pneumothorax after successful resolution following observation, needle aspiration, or tube drainage varies widely in published reports because of the varying age and associated respiratory disease patterns of the patients. The recurrence rate will also be influenced by whether the diagnosis is made on clinical or radiological grounds and the timing of attempts to produce pleural adhesion. Of 11 series with adequate reporting of recurrence rates, two had rates of $10-20 \%,{ }^{35}$ five of 20 $30 \%,{ }^{12678}$ and three of $30-50 \%,{ }^{9-11}$; the highest recurrence rate reported was $81 \% .^{12}$ After conservative management of their initial pneumothorax $39 \%$ of our patients suffered at least one further pneumothorax. Most series show a greater risk of recurrence after the second episode, with reported rates ranging from $45 \%$ to $80 \%^{12910}$; in our group the risk of recurrence after the second episode was $64 \%$.

Pneumothoraces on both sides at different times occurred in $12 \%$ of our cases; incidences of $6-15 \%$ have been reported by others. ${ }^{1314}$ The risk of a simultaneous bilateral pneumothorax appears low and occurred in $1.3 \%$ of our series, incidences of $2-2.5 \%$ having been reported previously. ${ }^{891115}$

Several reports have emphasised that the diseased area of the lung lies at the apex of the upper lobe and Lichter ${ }^{4}$ states that disease will be found only at this site in young adults. But in common with Brooks $^{8}$ and Saha et al $^{12}$ we found disease at other sites in several young adults and in a significantly greater number of patients when they had chronic obstructive lung disease.

In 1956 Gaensler $^{6}$ stated that there was no loss of pulmonary function after parietal pleurectomy and two years later Anderson and Poulson ${ }^{16}$ showed that there was no significant impairment of the mechanical efficiency of respiration. Like Singh, ${ }^{15}$ we found no significant change in the results of respiratory function tests performed before and six months or more after parietal pleurectomy.

Parietal pleurectomy, whether apical or full, is associated with a low incidence of recurrence. In eight series 4691113151718 with adequate follow up data there were 752 pleurectomies with only three recurrences $(0.4 \%)$, which is the same as our overall recurrence rate. It has been suggested by several authors that the recurrence rate after pleural abrasion is similar to that after pleurectomy. We have identified nine series of patients who had pleural abrasion with adequate follow up data. ${ }^{12}{ }^{19-26}$ In a total of 301 procedures there were seven recurrences $(2.3 \%)$, which is significantly more $\left(\chi^{2}=\right.$ $9.97, \mathrm{p}<0.005)$ than the four recurrences $(0.4 \%)$ occurring after a total of 988 pleurectomies (236 cases from our series and the 752 mentioned above).

We will discuss the complications encountered in our series from two points of view-firstly, in relation to features leading to increased morbidity and, secondly, comparing them with those reported in other series, bearing in mind the variation in defining complications and the differing patient populations. Overall complication rates for pleurectomy range from as low as $1.6 \%$ up to $16.4 \%$ for patients under 40 and $48.3 \%$ for those aged 40 and over. ${ }^{18}$ Few papers about pleural abrasion adequately report complications and some report mainly cases in children with cystic fibrosis. Quoted complication rates range from $3 \cdot 3 \%{ }^{21}$ to $11 \cdot 1 \%^{12}$.

One hundred and fifty five full pleurectomies gave rise to 36 complications $(23.2 \%)$-significantly more $\left(\chi^{2}=6.22, p<0.025\right)$ than the seven complications $(9.5 \%)$ occurring after 74 apical pleurectomies. The two groups were significantly different as regards the age (means 27.1 years versus 48.5 years: $t=3.54, \mathrm{p}<0.0005)$ and the presence of chronic obstructive lung disease $(10.4 \%$ versus 43.2\%: $\left.\chi^{2}=26 \cdot 1, p<0.0005\right)$. For each type of procedure the complication rate was greater in those with chronic obstructive lung disease: apical pleurectomy $7.4 \%$ versus $28.6 \%\left(\chi^{2}=3.30,0 \cdot 1<p\right.$ $<0.05)$, full pleurectomy $17.0 \%$ versus $31.3 \%\left(\chi^{2}\right.$ $=4.36, \mathrm{p}<0.05)$, and full pleurectomy plus decortication $28.6 \%$ versus $60 \% \quad\left(\chi^{2}=1 \cdot 18\right.$, not significant). If we exclude the decortication group $31.1 \%$ of those with chronic obstructive lung disease having a pleurectomy suffered complications whereas only $12.9 \%$ of those without chronic obstructive lung disease suffered complications, which is a significant difference $\left(\chi^{2}=10.6, p<0.005\right)$. We therefore conclude that it is the presence of chronic obstructive lung disease which accounts for the high complication rate in those having a full pleurectomy and not the procedure itself.

In patients both with and without chronic obstructive lung disease, tobacco smoking increased the complication rates. In the absence of chronic obstructive lung disease the rates were: non-smokers $4.5 \%$, smokers $18.9 \%\left(\chi^{2}=8.41, \mathrm{p}<0.005\right)$; and with chronic obstructive lung disease they were: non-smokers $28.6 \%$, smokers $41.4 \%\left(\chi^{2}=1.07\right.$, not significant). We believe that smoking increased morbidity but it was not as significant a factor as the presence of chronic obstructive lung disease.

Many series report no mortality, although a rate of $3.3 \%$ after pleurectomy has been reported in "older patients" 18 and a similar mortality rate after pleural abrasion has been reported. ${ }^{21}$ The cause of death in most reports is incidental to the operative procedure. The mean age of the three patients who 
died in our series was 71.2 years and all had chronic obstructive lung disease, although myocardial infarction, pulmonary embolism, and pneumonia with respiratory failure were the direct causes of death. Thus the mortality rate directly attributable to the pleurectomy was $0.4 \%$.

The usual incidence of bleeding leading to a haemothorax ranges from $0.7 \%{ }^{13}$ to $4 \cdot 4 \%,{ }^{27}$ with the highest reported rate $14.5 \% .^{26} \mathrm{Re}$-exploration for bleeding is uncommon and the highest reported rate was $3 \% .^{18}$ We re-explored two cases for persistent bleeding, a rate of $0.8 \%$-one in 74 apical pleurectomies $(1.4 \%)$ and one in 155 full pleurectomies $(0.6 \%)$.

The three basic methods of producing pleural adhesion are by induction of chemical pleuritis, by pleural abrasion, and by parietal pleurectomy. Chemical pleurodesis has been largely abandoned because of the high morbidity and recurrence rate. Pleurectomy is most often condemned when compared with pleural abrasion because, while the two methods are equally effective in preventing recurrence, pleurectomy is claimed to result in higher mortality and morbidity rates, especially increased blood loss and more risk of postoperative haemorrhage, and also because the dense nature of the adhesions are thought to be a disadvantage in case a further thoracotomy is required. In fact, the reported mortality and morbidity rates for the two procedures lie within the same range. There can be little additional trauma which might increase morbidity when the parietal pleura is stripped rather than abraded through a similar thoracotomy incision. In our experience the blood loss was of the same order as for other thoracotomies and in only two cases $(0.8 \%)$ was re-exploration for haemorrhage required. To be effective pleural abrasion must be to the point of "capillary oozing" and haemothorax and re-exploration for haemorrhage after abrasion have been reported.

We accept that the adhesions produced may be less dense after pleural abrasion than after pleurectomy and would thus make a further thoracotomy easier. We offer three comments on this point. Firstly, we have not had any patient who required further thoracotomy despite a reasonable proportion of patients in the age group in which bronchogenic carcinoma might be expected, and we note that there are only four recorded instances of the need for further thoracotomy. When Strieder (see discussion of paper by Mills and Baisch ${ }^{26}$ ) performed a further thoracotomy after a full pleurectomy he found the plane composed largely of avascular adhesions and reported no special problem with the second thoracotomy. Secondly, as we would advocate an apical pleurectomy in young adults it is reasonable to assume that the chest could be entered later through the area below the adhesions. Finally, if pleural abrasion is less likely than pleurectomy to prevent recurrence (which so far as we can determine is the case), the less dense adhesions produced may not be beneficial. We therefore make no apologies for advocating an operation that many authors, including Clagett, ${ }^{14}$ consider too radical.

Over the past few years the use of surgical staples rather than sutures to seal air leaks or excise areas of cyst formation has become common. We have used staples in some cases (not included in our results) and have not found them superior in preventing air leaks. They certainly produce a higher proportion of cases with no air leak immediately after operation but in our experience after suturing $94.2 \%$ of air leaks have ceased within 24 hours and in only two patients $(0.8 \%)$, both with chronic obstructive lung disease, did the leak persist for over four days. We do not consider the use of staples to be beneficial in terms of earlier discharge from hospital, particularly in view of the widely different costs and the multiple sites of cyst formation that are frequent in chronic obstructive lung disease.

In conclusion, we believe that the treatment of a spontaneous pneumothorax should take into account the underlying lung disease because this affects the tendency of the pneumothorax to recur. Fit young adults, who usually have apical disease, respond well to tube drainage, but since they have a tendency to suffer recurrences they should be considered for early surgery by apical pleurectomy if the air leak persists more than 72 hours. The older patients, many with chronic obstructive lung disease, often have widespread lung changes and respond less well to tube drainage, but have a lower recurrence rate, so a slightly more prolonged period of tube drainage, possibly up to 10 days, appears indicated before pleurectomy is performed. When a pleurectomy is carried out in patients with chronic obstructive lung disease, we would advocate a more extensive procedure than apical pleurectomy because of the more widespread cystic change.

We are most grateful to Mr AG Norman and Mr DG Taylor for allowing us to study their patients. Our grateful thanks also go to Miss Alison Ward for typing the manuscript.

\section{References}

${ }^{1}$ De Vries WC, Wolfe WG. The management of spontaneous pneumothorax and bullous emphysema. Surg Clin N America 1980;60:851-66.

${ }^{2}$ Ferguson LJ, Imrie CW, Hutchinson J. Excision of bullae without pleurectomy in patients with spontaneous pneumothorax. Br J Surg 1981;68:214-6. 
${ }^{3}$ Cran IR, Rumball CA. Survey of spontaneous pneumothoraces in the Royal Air Force. Thorax 1967;22:462-5.

${ }^{4}$ Lichter I. Long term follow-up of planned treatment of spontaneous pneumothorax. Thorax 1974;29:32-7.

${ }^{5}$ Singh SV. Current status of parietal pleurectomy in recurrent pneumothoraces. Scand J Thorac Cardiovasc Surg 1979;13:93-6.

- Gaensler EA. Parietal pleurectomy for recurrent spontaneous pneumothorax. Surg Gynaecol Obstet 1956;102:293-308.

${ }^{7}$ Reid JM, Stevenson JG, McSwan N. The management of spontaneous pneumothorax. Scott Med J 1963;8:171-4.

${ }^{8}$ Brooks JW. Open thoracotomy in the management of spontaneous pneumothorax. Ann Surg 1973;177: 798-805.

${ }^{9}$ Gobbel WG jun, Rhea WG jun, Nelson IA, Daniel RA jun. Spontaneous pneumothorax. J Thorac Surg 1963;43:331-45.

${ }^{10}$ Clark TA, Hutchinson DE, Deaner RM, Fitchett VH. Spontaneous pneumothorax. Am J Surg 1972;124: 728-31.

"Ruckley CV, McCormack RJM. The management of spontaneous pneumothorax. Thorax 1966;21:139-44.

12 Saha SP, Arrants JE, Kosa A, Lee WH jun. Management of spontaneous pneumothorax. Ann Thor Surg 1975;19:561-4.

${ }^{13}$ Deslauriers J., Beaulieu M, Despres JP, Lemieux M, LeBlanc J, Desmeules M. Trans-axillary pleurectomy for treatment of spontaneous pneumothorax. Ann Thorac Surg 1980;30:569-74.

${ }^{14}$ Clagett OT. The management of spontaneous pneumothorax. J Thorac Cardiovasc Surg 1968;55:761-2.

${ }^{15}$ Singh SV. The surgical treatment of spontaneous pneumothorax by parietal pleurectomy. Scand $J$
Thorac Cardiovasc Surg 1982;16:75-80.

${ }^{16}$ Anderson I, Poulson T. The surgical treatment of spontaneous pneumothorax. Acta Chir Scand 1959;118: $105-112$.

${ }^{17}$ Askew AR. Parietal pleurectomy for recurrent pneumothorax. Br J Surg 1976;63:203-5.

${ }^{18}$ Saha D. Parietal pleurectomy for prevention of recurrent spontaneous pneumothorax. $\mathrm{Br} J$ Dis Chest 1964;58:78-83.

${ }^{19}$ Rich RH, Warwick WJ. Leonard AS. Open thoracotomy and pleural abrasion in the treatment of spontaneous pneumothorax in cystic fibrosis. $J$ Paediatr Surg 1978;13:237-42.

${ }^{20}$ Stowe SM, Boat TF, Mendelsohn $\mathrm{H}$, et al. Open thoracotomy for pneumothorax in cystic fibrosis. Am Rev Respir Dis 1975;111:611-7.

21 Youmans CR jun, Williams RD, McMinn MR, Derrick JR. Surgical management of spontaneous pneumothorax by bleb ligation and dry sponge abrasion. $A m \mathrm{~J}$ Surg 1970;120:644-8.

${ }^{22}$ Baronofsky ID, Warden HG, Kaufman, JL, Whatley J, Hanner JM. Bilateral therapy for unilateral spontaneous pneumothorax. J Thorac Surg 1957;34:310-22.

${ }^{23}$ Seremitis MG. The management of spontaneous pneumothorax. Chest 1970;57:65-8.

${ }^{24}$ Driscoll PJ, Aronstam EM. Experiences in management of recurrent spontaneous pneumothorax. $J$ Thorac Cardiovasc Surg 1961;42:174-8.

${ }^{25}$ Neal JF, Vargas G, Smith DE, Aki BF, Edwards WS. Bilateral bleb excision through median sternotomy. Am J Surg 1979;138:794-7.

${ }^{26}$ Mills M, Baisch BF. Spontaneous pneumothorax. A series of 400 cases. Ann Thorac Surg 1965;1:286-97.

${ }^{27}$ Thomas PA, Gebauer PW. Results and complications of pleurectomy for bullous emphysema and recurrent pneumothorax. J Thorac Surg 1960;39:194-201. 